\title{
Board Member Perceptions of Small Nonprofit Organization Effectiveness
}

\author{
Laura Levy Maurer \\ Walden University
}

In contemporary American society, the nonprofit board is accountable for ensuring that an organization has sufficient resources to carry out its mission. Filling the gap between demands for services and the resources to meet them is often a struggle for small nonprofit organizations, a problem of nonprofit organization effectiveness. I conducted a hermeneutic phenomenological study that examined how board members of small local nonprofits in the focal community perceived nonprofit organization effectiveness. A review of the literature revealed that nonprofit organization effectiveness involved the action of contributing to the organization and the motivation behind the action, both of which were associated with trust and reciprocity. Guided by social constructivism this research involved a qualitative analysis of repeated iterations of semiotic data from board members $(n=30)$ and text analysis of organization mission statements $(n=21)$, generating thick description of board members' understanding of effectiveness. The analysis revealed that strategies focused on developing reciprocity and mitigating mistrust among board members contributed to board members perceiving their organizations as effectively achieving their objectives. Application of the findings and conclusions, developed from the lived experiences of members of small nonprofit boards, contributes to social change among small American nonprofit organizations by suggesting means to address the stresses that compromise the availability and quality of their programs.

Keywords: nonprofit organization, board members, effectiveness, qualitative study, phenomenology

\section{Introduction}

As social science researchers, we are at the intellectual cusp of social change. When it comes to transferring the results of our research to practical application we use local nonprofit organizations as the agents of application (Nonprofit Research Collaborative [NRC], 2012). This broaches the subject of the nature of local nonprofit organizations themselves. Local nonprofit organizations are responsible for filling the gap between community demands for services and the resources to fulfill them: a problem of organization effectiveness (Schultz \& Williams, 2010). Uncertainty about how American nonprofit organizations meet this challenge led to social science investigations into the effectiveness of organizations that were part of the nonprofit sector (Barman, 2008). Social scientists are in the process of developing a body of research on those responsible for nonprofit organization operations, namely nonprofit boards of directors (Jacobs \& Polito, 2012). Marx and Davis (2012) suggested that social scientists could define nonprofit organization effectiveness by determining what nonprofit organization boards of directors actually did in the course of their real world operations. 
Barman (2008) stated that American nonprofit organizations were increasingly responsible for providing social services previously administered by municipalities. The Portland Business Journal stated that philanthropic contributions were essential on covering the gap left by funding cutbacks throughout the previous 10 years (Cheney, 2012). According to the NRC, $65 \%$ of American nonprofit organizations reported increased demands for services in 2011 compared with 2010 . The current situation facing American nonprofit organizations is one of reduced support, from both government and private sources, combined with increased demands for services (NRC, 2012). Nonprofit organizations, a subset of voluntary organizations, were the focal organizations of this study.

Sociologist Max Weber (1964) provided that the basic tenets for understanding human interaction included both that people behaved as subjective beings and that their behaviors affected the behaviors of others. He substantiated the concept of voluntary organizations as amenable to empirical study. Berger and Luckman (1967) assumed that social scientists could study people's experiences and that people were conscious of their lived experience. Contemporary social scientists recognize that people build up, or socially construct, a shared version of reality. From the social constructivist perspective human interaction was framed by societal practices, rather than norms. These practices lent themselves to understanding by studying the manifestations of interaction including words, texts and symbols (Bourdieu, 1990). From this I assumed that I could construct a detailed picture of the phenomenon of nonprofit organization effectiveness by studying the semiotic practices of the members of boards of directors of small nonprofit organizations.

A corollary assumption was that meaning could only be understood in context (Luhmann, 1995). The specific context of this study was the American small, local nonprofit organization. The justification for focusing the study research on small, local nonprofits was as follows. It made transparent the philosophical force that directed the selection of the study topic, namely that it would have a connection to the possibility of social change and implications for social change practitioners. Contemporary medium to large American nonprofit organizations have regional and national constituencies and presence. Their directors are spatially and temporally removed from their sites of service delivery. They are sophisticated organizations with complex infrastructures that have more features of compulsory organizations than voluntary organizations according to Weber's (1964) typology (LeBlanc \& Gilles, 2005). The probability that the results and findings of this study would find an audience amenable to social change among the constituencies of large American nonprofit organizations was small compared with finding opportunities for pragmatic application within the community of small, local nonprofit organizations.

According to Schefczyk and Peacock (2010), nonprofit organization effectiveness included both the action of helping and the intent that motivated the action. They described the motivational condition as a reasoned approach to benefitting others. Berger and Luckmann (1967) introduced the concept of reciprocity as critical to understanding how people came to shared understandings of social situations. People reciprocally shared social expectations. Shared reciprocal expectations helped determine how people came to take care of the needs of others. Trust was implicit in reciprocal transactions because the parties had to trust one another to meet their obligations (Blau, 1964).

Strategies engendering trust and reciprocity became part of the seemingly naturally appearing rules of conduct that guided people's day-to-day activities (Bourdieu, 1990; Rice, 2008). Thomas and Medina (2008) determined that reciprocal interpretation of their focal concept, diversity, engendered trust between the constituents and the organization. In turn, the efforts of the organization's board were reciprocated by furthering its community influence. Krueger, Massey, and DiDonato (2008) 
found from a mathematical analysis based in game theory that trust was a strategy applied to enhance social reputation, even at the expense of monetary return. Community members who trusted that their favorable actions would be reciprocated became a group of practitioners whom the community could call upon during exigencies. An organized group of such practitioners was the board of a local nonprofit organization. In the contexts of this theoretical background, its significance to current investigations, and contemporary practice the question I posed for this study was, "How do board members of small local nonprofit organizations perceive nonprofit organization effectiveness?"

\section{Method}

The purpose of the study was to understand what constitutes small nonprofit organization effectiveness. I undertook a phenomenological inquiry into what it meant to be an effective small, local nonprofit organization in a community of about 15,000 in population in central Arizona based on the perceptions and experiences of the members of their boards of directors. I uncovered, in an iterative fashion, how the process of becoming (or not becoming) an effective local nonprofit organization unfolded. I ascertained the underlying structure of nonprofit organization effectiveness by looking for themes and patterns that emerged from the empirical manifestation of interpersonal communication, including words, texts, and symbols (Marx \& Davis, 2012). To get at the essence of the focal phenomenon, I used iterative coding to distill meaningful themes and patterns from data derived from sets of responses from respondents who were members of boards of directors of local nonprofit organizations, organization mission statements and researcher reflection (Holton, 2010; Olszewski, Macey, \& Lindstrom, 2007).

I defined nonprofit organizations as follows. They were voluntary organizations that had nonprofit or charitable legal status, an IRS designation of 501c(3), and were governed by boards of directors. Local nonprofit organizations had all of the preceding characteristics and delivered programs and services to their local communities. Small, local nonprofit organizations had all of the preceding characteristics and were located in and served communities of less than 15,000 in population and had annual operating budgets of less than $\$ 400,000$.

I conducted the investigation according to Eberle's (2010) assumptions of construct-centered research. Eberle's assumptions required that the study was logically consistent, relevant, related to understanding subjective social interaction, and adequate, meaning that the constructs that social scientists agreed on also had to be intelligible to common sense experiences of nonscientists. Creswell (2009) agreed. He took the position that validity of construct-centered studies could be assessed by determining whether researchers, study participants, and readers of the findings found them accurate. Using NVivo10 (QSR, International, 2012) software allowed me to gather, store, and analyze information on the key constructs using a vehicle that was accessible and transparent to other researchers and community members.

Ebrahim (2009) ascertained that recent strategies within the nonprofit sector to reduce uncertainty have focused on the organizations' boards, especially in the United States. This study focused on nonprofit organization boards. I used the approach to sampling that qualitative researchers identified as purposeful sampling (Corbin \& Strauss, 2008; Gerring, 2007). I did not sample randomly from all of the adults in the focal community. I contacted people who had the capicity to inform my study purpose, members of boards of directors of local nonprofits. I also sampled text in the form of mission statements of the organizions. 
I looked for common ideas about nonprofit effectiveness among the experiences and perceptions of study respondents, members of nonprofit organization boards directors. I synthesized thick description, a combination of observation and interpretation, to help understand problems and solutions associated with nonprofit organization effectiveness in ways that attached directly to practice. Scerri and James (2010) found that qualitative methods were more likely to actively engage people interested in nonprofit activities in achieving organizational effectiveness in their own communities.

I communicated with participants electronically, via email, rather than face-to-face. I informed the respondents in writing that my research was not intended to prove or disprove a particular hypothesis or point of view. In this way I methodologically bracketed my personal biases from the conduct of the research (LeBlanc \& Gillies, 2005).

\section{Participants}

I started with a list of the 123 registered 501c(3) organizations in the focal community. The organizations included secular human services providers, public elementary schools, arts organizations, environmental organizations, animal protective services providers, and faith-based human services providers. I eliminated organizations whose names indicated that their services did not take place in the focal community. I used the remaining 100 organizations' URLs as obtained from a Google search. Through the websites of these organizations, I obtained information for 90 individuals on boards from 49 different organizations. I contacted all board members for whom the organizations' URLs provided email addresses. I did not make any exceptions. I contacted each person via the electronic contact information provided by the organizational website. Thus, all contact information came from publicly available sources.

In the email to the 90 board members, I told them that the study was about effectiveness of small nonprofit organizations and that as board members of small nonprofits they were eligible to participate in my study. I requested their responses to a set of questions. From my initial request, I collected responses to a set of questions via email from 30 members of 21 boards of directors of local nonprofit organizations. The fact that $33 \%$ of the original contact group responded made me confident that I had a sufficient sample. I entered the entire content of the sets of repsonses into NVivo10.

\section{Instrumentation}

I used two data collection instruments: responses to a set of questions sent and received via email and analysis of organization mission statements. See the Appendix for the set of questions. I obtained mission statements directly from organization web sites. I entered the content of the mission statements into NVivo10. Simultaneously I recorded my experiences and interpretations in the form of a reflective journal using the Memo function of NVivo10. I assigned a number to each completed set of responses. I entered all raw data into NVivo10 using the number as the sole identifier. I contacted respondents by email to ask if they had any questions. I answered their questions and gave them a chance to modify their responses. I then deleted the emails.

\section{Data Analysis}

I went through each of the responses individually asking myself what was the underlying meaning of each. By this means I identified topics that emerged from the raw data. I used the topics to generate 
codes (Kohlbacher, 2006). I used licensed and password protected NVivo10 (QSR, 2012) software. NVivo10 facilitated my ability to store, track, and retrieve data sources in all formats in a single database (Baxter \& Jack, 2008). I used the next round of coding to analyze the balance between items coded to similar codes versus those that fell into unique or unanticipated categories. I further analyzed the new categories to determine the nature and consistency of the data attributed to these categories. I combined the results of this analysis with those of the first. I continued this pattern until the same codes and assignments of data started repeating. I then added the results of the document analysis of organization mission statements.

\section{Results}

\section{Theme 1: Actions Associated With Board Members' Perceptions of Nonprofit Organization Effectiveness}

\section{Cohesion and Compromise}

The actions of cohesion and compromise emerged through multiple iterations of the data. A respondent described an effective board as fostering a "conglomeration of attitudes that comes together for a greater cause and manages to be cohesive."

\section{Work}

I initially assigned process as a code to capture expressions of action. The definition of process was "a series of actions or operations definitely conducting to an end" ("Process," 2014, p. 791). I used participation as a code for common action to capture the nature of organizational, as opposed to individual, effectiveness. Its definition was "having a share in common with others" (Participation," 2014, p. 723). The initial coding elicited only one action word, work, exemplified by a respondent's statement that "members worked together even if their individual recommendations had been outvoted." I eliminated the codes Process and Participation and assigned work, cohesion, and compromise as codes for action.

\section{Actions of Ineffective Boards}

Another theme that emerged was that the respondents described actions of boards that were not effective almost as frequently as those of effective boards. For example, one respondent said that an effective board had to work "without hostility and acrimony, not micromanage the nonprofit."

\section{Theme 2: Motivations Associated With Board Members' Perceptions of Nonprofit Organization Effectiveness}

\section{Commitment}

I assigned the code of Commitment to capture empirical evidence of motivation. This code was easier to recognize because it did not refer to abstracted concepts such as process. I coded over $7 \%$ of the total content of the raw data to the Commitment code. A respondent's description became the working definition of commitment: "every board member cares deeply about the success of the organization and contributes substantially to its functioning."

\section{Reemergence of Work}

As with action, the descriptions of work and descriptions of boards that were the opposite of motivated also emerged as patterns. One respondent described motivated board members as those "willing to work for the greater good of the organization's goals and members." 


\section{Attributes of Unmotivated Boards}

One respondent described the opposite of motivation as board members "not willing or able to operate for the betterment of the organization or in one instance by being asked to leave." I integrated the theme of opposite when I analyzed trust and reciprocity by looking for empirical instances of the opposite of these concepts.

\section{Theme 3: Mistrust}

My analysis of the first round of coding related to trust revealed an unanticipated outcome. All of the responses referred to instances of the opposite of trust. I changed the name of the coding category to Mistrust. One respondent described a mistrusted board member as one who had "no common sense, reason, or dedication and is a burr under everyone's saddle." The creation of the code Mistrust led me to create another code called Imbalance to capture what was not reciprocity.

\section{Theme 4: Reciprocity}

Prior to initial coding, I decided to code all references to reciprocity to a code called Networks and Relationships. This decision proved problematic. My initial coding resulted in a lot of duplication. I performed an immediate second round of coding by eliminating Networks and Relationships and coding directly to Reciprocity. The result was that I coded $12.7 \%$ unduplicated content of the total content of the 30 sets of responses to the code Reciprocity.

\section{Common Expectations and Obligations}

Most of the content about reciprocity referred to common expectations between board members. One respondent articulated the reciprocal expectation that "each board member attends board meetings and shares his/her thoughts and ideas and interacts with other board members, contributes to reaching a consensus, and works as a team to divide the workload".

\section{Reciprocity and Work}

Another respondent said, "board members are accountable to one another to do the agreed upon work." One respondent summed up the relationship between reciprocity and work with the following: "each member realizes that the board's accomplishment requires team work and has a desire to be part of that team." The element of work revealed itself as integral also to the concept of reciprocity.

\section{Imbalance}

As noted, I created a code of Imbalance to capture instances of the antithesis of reciprocity. The construct of Imbalance was exemplified by the following statement: "everyone has an opportunity to speak and not have one person or two monopolize the meetings." It contained both a description of what reciprocity is, "everyone has an opportunity to speak" and what it is not, "not have one person or two monopolize the meetings." The following statement sums up the concept of imbalance: "[fellow board members] do not seem to know that individuals on an executive board should have at least 'some' involvement in organizational duties."

\section{Theme 5: Community}

The word community was among the most frequently used words within the raw data. A word search revealed the contexts cited by the respondents that encompassed community. One respondent summed up the essence of board effectiveness and community as follows: "an effective board is one 
which generally focuses on building/creating tools for their community that serves to empower that community long after those board members' terms have been served.”

The next most frequent word was mission. Analysis of the contexts where respondents referred to mission revealed that respondents used it in tandem with the word commitment. The emergence of organizational mission provided empirical justification for the selection of analysis of mission statements as a means of triangulation.

\section{Analysis of Mission Statements}

Table 1 synthesizes the mission statements of 21 different nonprofit organizations into a common statement that "our mission is to provide projects and services to our local community." In terms of the mission, the sense of community was integral among the represented small nonprofit organizations.

Table 1: Words Used 10 Times or More in Mission Statements

\begin{tabular}{lc}
\hline Word & Number of instances \\
\hline Community & 29 \\
Mission & 13 \\
Local & 11 \\
Services & 11 \\
Project & 10 \\
\hline
\end{tabular}

\section{Discussion}

\section{Theme 1: Actions-Work, Cohesion, and Compromise}

According to the respondents, cohesion, compromise, and work were actions that were part of nonprofit organization effectiveness. One respondent summarized these themes by noting that board members contributed to a "conglomeration of attitudes that comes together for a greater cause and manages to become cohesive even when individual attitudes vary."

\section{Theme 2: Motivations-Commitment}

According to this group of respondents, commitment motivated nonprofit organizational effectiveness. This theme of commitment was synthesized by one respondent as "every board member cares deeply about the success of the organization and contributes substantially to its functioning."

Work

The element of work was integral to action and motivation. One respondent defined work in the context of small local nonprofits as "tackling each assignment with zeal." This interpretation of work in the context of the study is not identical to its colloquial interpretation. This should catalyze further inquiry. 


\section{Theme 3: Mistrust}

The study findings about trust revealed that an element of mistrust among small nonprofit board members may be more pervasive that either the theoretical literature or recent research has revealed (Ebrahim, 2009; Giddens, 1990; Glanville \& Bienenstock, 2009). I inferred from the study data that trust was not a taken for granted element of small, local nonprofit organization boards in the focal community. Practices that mitigated mistrust had to be continuously addressed in order for the organizations to be effective. Trust emerged from the data analysis as a strategy to eliminate mistrust. Respondents suggested that such a strategy could be built up by using common sense, as well as intelligence, discipline, thoughtfulness, and respect.

\section{Trust}

The study data that described mistrust did not confirm the understanding derived from the literature that the board members would not be exploited in the context of the small local nonprofit organizations (Buchan, Croson, \& Dawes, 2002; Molm, Schaefer, \& Collett, 2007). Respondents did not trust that other board members would not exploit them. Trust may be a fluid concept ranging from complete trust to complete mistrust depending upon the context. It appears that trust could be built up as board members experienced common activities that achieved organizational objectives. Further study is needed to clarify the nature of trust.

\section{Theme 4: Reciprocity}

Based on the results of this investigation, an integrated definition of reciprocity in the context of small nonprofit organization boards is sharing of mission, ideas, work, and accountability in an atmosphere of reason and respect.

\section{Common Expectations and Obligations}

Most of the content about reciprocity referred to common expectations between board members. Reciprocal obligations and expectations expressed by respondents were that board members "have common sense, listen, and be reasonable" and have the "willingness to share work and responsibility and accountability.”

\section{Theme 5: Community}

Community was the unifying theme among all 21 organizations, regardless of individual organization focus. Community appeared in mission statements two and a half times more often than any other word, including mission. Regardless of individual differences of attitudes, opinions, and perspectives a common commitment to the mission of the organization was critical to organization effectiveness.

\section{Implications for Practice for Contemporary Local Nonprofit Organizations}

Application of the findings and conclusions, developed from the lived experiences of members of small nonprofit boards, contributes to social change among small American nonprofit organizations by suggesting means to address the stresses that compromise the availability and quality of their programs. An article in the New York Times (Smith, 2013) provided empirical evidence of an ineffective nonprofit organization board and the potential for action to turn itself around. The article stated that for the past 5 years the nonprofit organization "was being run into the ground" (p. C-1). 
The board members did not grasp either the cultural significance or the immediate financial instability of the organizational infrastructure. Not only were they not committed to the organization's mission, they had no clear conception of a mission. The board was dominated by a single member. That is, there was no strategy of cohesion or compromise. There was no equitable distribution of the workload and accountability to do the agreed upon work. In experiential terms, the board members were operating in circumstances of imbalance and mistrust.

The reporters described an organization experiencing the stresses that threatened not only its ability to provide services to its community, but its very existence. In order to extricate itself the board instituted measures to become more effective in practice. The motivations, strategies and actions of the board in this example were a mirror of the findings of this study that developing reciprocity and mitigating mistrust among board members were critical elements in nonprofit organization effectiveness both in theory and in practice.

The board had to reassert its mission by developing a reciprocal understanding, as a unit, of the cultural significance of the organization to the local community and the organization's financial stability. In other words, the board as a whole had to recognize and accept its nature as the fiduciary agent of the nonprofit entity. Once the board members expressed their willingness to share work, responsibility and accountability they put themselves in a position to articulate a clear and succinct statement of mission.

Having successfully engaged in the give and take necessary to create the mission statement the board members experienced the phenomenon of reciprocity out of which they could build a shared history of and protocol for cohesion and compromise. The board members had to recognize that effectiveness was not being achieved when personal agendas overrode those of the organization. With this in mind the board members could institute action aimed at building up trust. The starting point for their experience of effectiveness as a nonprofit organization board was grounded in reciprocity and trust.

The board members described in the article agreed to cull their numbers "to those who really cared and were willing to commit enormous energy" to achieving the mission of the nonprofit organization (Smith, 2013, p. C-1). Board members of local nonprofit organizations who agree to improve their effectiveness can employ similar strategies when they set out to recruit and retain board members. A passionate commitment to the cultural significance of the organization to the local community and the willingness to work diligently to support the financial stability of the organization must be paramount to the board both as individual members and as a unit.

The shared commitment to the organization and its mission converts individual board members into a team. The board in the example reached the consensus that it had to decrease its number of members in order to fortify itself. Other boards may decide to increase their membership to achieve the same results.

To minimize mistrust and build reciprocity board members must take steps to ensure that their peers are forthcoming about their motivations and have no expectation of personal gain. Otherwise, as one respondent put it, when desires for personal gains are "denied by those board members who are actively competing [they are] derailing the mission of the organization." As a respondent stated, "credit must be given and acknowledged where credit is due," for board members to build the foundation for future experiences of reciprocity and trust. 
Board members who will contribute to the effectiveness of the nonprofit organization are expected to diligently carry out assigned tasks. According to a respondent, "the organization cannot be effective if a few of the board members run the organization with little participation of the others." In short members of effective boards of small, local nonprofit organizations are expected to share their thoughts, reach consensus, divide the workload, be respectful of fellow board members and the organization, and have shared vision of a greater purpose. The boards of small, local nonprofit organizations can use these criteria for setting their own strategies for recruitment and retention of board members.

\section{The Meaning of Nonprofit Organization Effectiveness}

The study contributed to a sociological understanding of the meaning of nonprofit organization effectiveness. One participant summed up nonprofit organization effectiveness as a "belief, passion, and commitment for the mission of the nonprofit organization achieved by continual review of the mission and vision statements, combined with awareness of the duties of board members and what is expected of them." This statement embodies and expresses the key themes of this study: action, motivation, reciprocity, and trust.

The study results engender information that can help scholars, practitioners, service consumers, service deliverers, and funders, distinguish between effective and ineffective small nonprofit boards of directors. Boards of nonprofit organizations that adapt strategies of reciprocity and trust consonant with their community contexts will be likely to be perceived as effective in providing their programs and services, which, in turn, may forward their missions to fill the gap between external demands for service and the resources to provide them (Ebrahim, 2009).

The respondents experienced cohesion, consensus, and compromise when they focused on their common commitment to improving their community. In their own words, effective nonprofit organizations had board members who were "always_respectful of one another, [and] the organization mission, and have a shared vision of a greater purpose, [and] the willingness to work with responsibility and accountability." Effective boards of small nonprofit organizations "focus on building and creating tools for their community that serve to empower that community." Such boards can, are, and will continue to be local catalysts for social change. 


\section{References}

Barman, E. (2008). Organizational genesis in the nonprofit sector: An analysis of demand, supply, and community characteristics. International Journal of Organization Theory and Behavior, $11,37-60$.

Baxter, P., \& Jack, S. (2008). Qualitative case study methodology: Study design and implementation for novice researchers. The Qualitative Report, 13, 544-559. Retrieved from www.nova.edu/ssss/QR/QR-13-4/baxter.pdf

Berger, P. L., \& Luckmann, T. (1967). The social construction of reality: A treatise in the sociology of knowledge. Garden City, NY: Doubleday and Company.

Blau, P. (1964). Exchange and power in social life. New York, NY: Wiley.

Bourdieu, P. (1990). The logic of practice. Stanford, CA: Stanford University Press.

Buchan, N. R., Croson, R. T. A., \& Dawes, R. M. (2002). Swift neighbors and persistent strangers: A cross-cultural investigation of trust and reciprocity in social exchange. American Journal of Sociology, 108, 168-206.

Cheney, C. (2012, October 26). Oregon's biotech sector shows signs of life. Portland Business Journal, Section 2, page 1.

Corbin, J., \& Strauss, A. (2008). Basics of qualitative research, 3e, techniques and procedures for developing grounded theory. Thousand Oaks, CA: Sage Publications.

Creswell, J. (2009). Research design: Qualitative, quantitative and mixed methods approaches, (3rd ed.). Thousand Oaks, CA: Sage Publications.

Eberle, T. S. (2010). Phenomenological lifeworld analysis and the methodology of the social sciences. Human Studies, 33, 123-139. doi:10.1007/s10746-101-9146-9

Ebrahim, A. (2009). Placing the normative logic of accountability in "thick" perspective. American Behavioral Scientist, 52, 885-904. doi:10.1177/0002764208327664

Giddens, A. (1990). The consequences of modernity. Stanford, CA: Stanford University

Glanville, J. L., \& Bienenstock, E. J. (2009). A typology for understanding the connections among different forms of social capital. American Behavioral Scientist, 52, 1507-1530. doi:10.1177/0002764209331524

Gerring, J. (2007). Case study research principles and practice. New York, NY: Cambridge University Press.

Holton, J. (2010). The coding process and its challenges. The Grounded Theory Review, 9, 21-40. doi:10.4135/9781848607941

Jacobs, G. A., \& Polito, J. A. (2012). How faith-based nonprofit organizations define and measure organizational effectiveness. International Journal of Organization Theory and Behavior, 15, $29-56$.

Kohlbacher, F. (2006). The use of qualitative content analysis in case study research. Forum: Qualitative Social Research, 7, 21. Retrieved from http://www.qualitativeresearch.net/index.php/fqs/article/view/75/153 
Krueger, J. I., Massey, A. L. \& DiDonato, T. E. (2008). A matter of trust: From social preferences to the strategic adherence to social norms. Negotiation and Conflict Management Research, 1, 31-52. doi:10/1111/j.1750-4716.2007.00003.x

LeBlanc, R. \& Gillies, J. (2005). Inside the boardroom: How boards really work and the coming revolution in corporate governance. Mississauga, Ontario: John Wiley and Sons, Ltd.

Luhmann, N. (1995). Social systems. Stanford, CA: Stanford University Press.

Marx, J., \& Davis, C. (2012). Nonprofit governance: Improving performance in troubled economic times. Administration in Social Work, 36, 40-52. doi:10.1080/03643107.2010.550670

Molm, L. D., Schaefer, D. R., \& Collett, J. L. (2007). The value of reciprocity. Social Psychology Quarterly, 70, 199-217. doi:10.1177/019027250707000208

Nonprofit Research Collaborative (NRC). (2012). Special Report Engaging Board Members in Fundraising. Retrieved from http://www.npresearch.org/pdf/earlier-reports/NRC-BoardEngagement-Report-Sept-2012.pdf

Olszewski, B., Macey, D., \& Lindstrom, L. (2007). The practical work of <coding>: An ethnomethodological inquiry. Human Studies, 29, 363-380. doi:10.1007/s/10746-006-9029-2

Participation. (2014). In Merriam-Webster collegiate dictionary. Springfield, MA: Merriam-Webster, Inc.

Process. (2014). In Merriam-Webster collegiate dictionary. Springfield, MA: Merriam-Webster, Inc.

QSR International. (2012). NVivo 10 [Computer software]. Victoria, Australia: Author.

Rice, J. G. (2008). Icelandic charity donations: Reciprocity considered. Ethnology, 46, 1-20.

Scerri, A., \& James, P. (2010). Accounting for sustainability: combining qualitative and quantitative research in developing "indicators" of sustainability. International Journal of Social Research Methodology, 13, 41-53. doi:10.1080/13645570902864145

Schefczyk, M., \& Peacock, M. (2010). Altruism as a thick concept. Economics and Philosophy, 26, 165-187. doi:10.1017/S0266267110000180

Schultz, L. S., \& Williams, M. J. (2010, January 28-29). Philanthropy in today's world. Paper presented at the Sustainable Funding Institute symposium, Sedona Community Center, Sedona, AZ.

Smith, R. (2013, March 22). For a museum on the ropes survival means hard choices. New York Times. Retrieved from http://www.nytimes.com/2013/03/23/arts/design/los-angeles-moca-at-acrossroads.html?_r=0

Thomas, R. L., \& Medina, C. K. (2008). Leveraging social capital among organizations to secure employment for welfare clients. Journal of Community Practice, 16, 271-291. doi:10.1080/10705420802255007

Weber, M. (1964). The theory of social and economic organization. New York, NY: Free Press. 


\section{Appendix}

\section{Protocol for Email Set of Questions}

What is the main goal of your board?

What has been your experience of an effective nonprofit board of directors?

How would you describe the effectiveness of your fellow board members?

Thinking of the board as a whole, rather than individual members, how would you describe an effective board that you have been on or observed?

To protect your privacy no consent signature is requested. Instead, you may indicate your consent by returning the complete set of responses directly to me at the email address of this correspondence.

The Journal of Social, Behavioral, and Health Sciences is an open-access, peer-reviewed, online interdisciplinary journal focusing on research findings that address contemporary national and international issues. Its objectives are to (a) encourage dialogue between scholars and practitioners in the social, behavioral, and health sciences that fosters the integration of research with practice; (b) promote innovative models of interdisciplinary collaboration among the social, behavioral, and health sciences that address complex social problems; and (c) inform the relationship between practice and research in the social, behavioral, and health sciences.

Walden University Publishing: http://www.publishing.waldenu.edu 